\title{
UNIVERSAL TUNABLE CURRENT-MODE BIQUAD EMPLOYING DISTRIBUTED FEEDBACK STRUCTURE WITH MO-CCCII
}

\author{
Roman Šotner — Josef Slezák — Tomáš Dostál — Jiří Petržela *
}

\begin{abstract}
One possible application of the multiple-output electronically-tunable active building block as a universal filter with distributed feedback structure is presented. The suggested structure is less conventional than the well-known state-variable Kerwin-Huelsman-Newcomb but allows the same filter configurations with the similar properties. The major current-mode design approach disadvantage, $i e$, the necessity of multiple current outputs, is demonstrated. To date even a rather big line of the commercially available devices do not solve this problem. Some features of the active block used for modelling and transistor-level simulation are briefly discussed. The obvious chance for electronic tuning of the proposed filter is verified.
\end{abstract}

K e y w ords: current-mode, universal biquad, multi-output current conveyors, electronic adjusting

\section{INTRODUCTION}

In the case of current-mode $(\mathrm{CM})$ circuits there is always a requirement to make a copy of the output current [1] into different directions (towards feedback, for summing function, etc). Generally, CM realizations are significantly simpler if compared with dual voltage-mode (VM) counterparts. This is mainly due to the elemental realization of the summing operation by a single node. On the other hand, the biggest obstacle is an implementation of the multiple-current outputs with both polarities next to the active block or in the so-called current distributor [2]. Recently, many integrated circuits suitable for CM applications up to the video frequencies are accessible, few of them with electronic tuning. Unfortunately, the lack of the multiple current outputs makes them less universal. Let us briefly discuss some examples. First, a voltagecontrolled current multiplier (or second generation negative current conveyor CCII-) EL2082 is mentioned in [36 , the well known and widely used trans-resistance amplifier AD 844 is utilized in [7]. It seems that the most potential is behind the trans-conductance amplifiers (OTA) $[3,8]$. OTA followed by a current-feedback amplifier is covered by LT 1228 [9] and a diamond transistor with a voltage buffer can be recognized inside OPA 860 [10]. Referring to the best knowledge of the authors, the only active device with two current outputs (balanced) is OTA marked as MAX 435 [11]. This block is not recommended for new designs since its manufacturing process has been stopped.

Although this paper (especially proposed active building block) looks similar to [12], there are many fundamental improvements. The authors in [12] state that their circuit can be adjusted electronically but, in fact, notable the frequency and quality factor are adjusted by changing the resistors. Moreover, the filter is verified only in the low frequency range. Thus, a practical benefit of this "novel filter is disputable to say the least. Such conglutinate of the external transistors will have substantial parasitic effects. The circuitry proposed in this article has less passive elements (only two resistors and two capacitors). Of course, there is a possibility to make a multiple output performance by using several single-output devices with parallel high-impedance inputs but at the cost of raising the complexity of the network [13]. Such a solution takes a lot of place, it is necessary to work out a more complicated electronic adjusting (which is often simultaneous) and the final price is much bigger. (a)

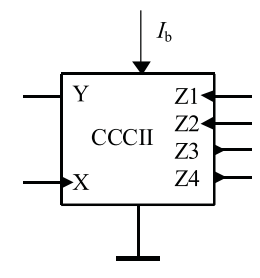

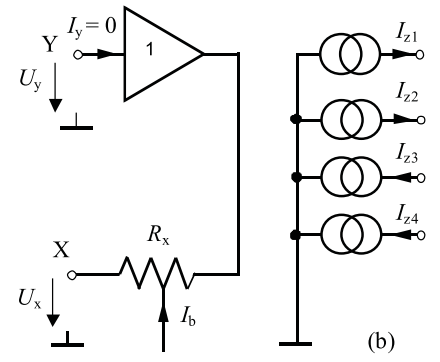

(b)
Fig. 1. Schematic symbol and the simplest behavioural model of MO-CCCII

In practice, it is quite simple to create a chips internal structure with multiple outputs by adding a proper number of current mirrors. In spite of this, the manufacturers are focused on developing a standard voltage-feedback (VFA) and current-feedback (CFA) amplifiers with a high

\footnotetext{
* Department of Radio Electronics, University of Technology Brno Purkynova 118, 61200 Brno, Czech Republic xsotne00@stud.feec.vutbr.cz, petrzelj@feec.vutbr.cz
} 


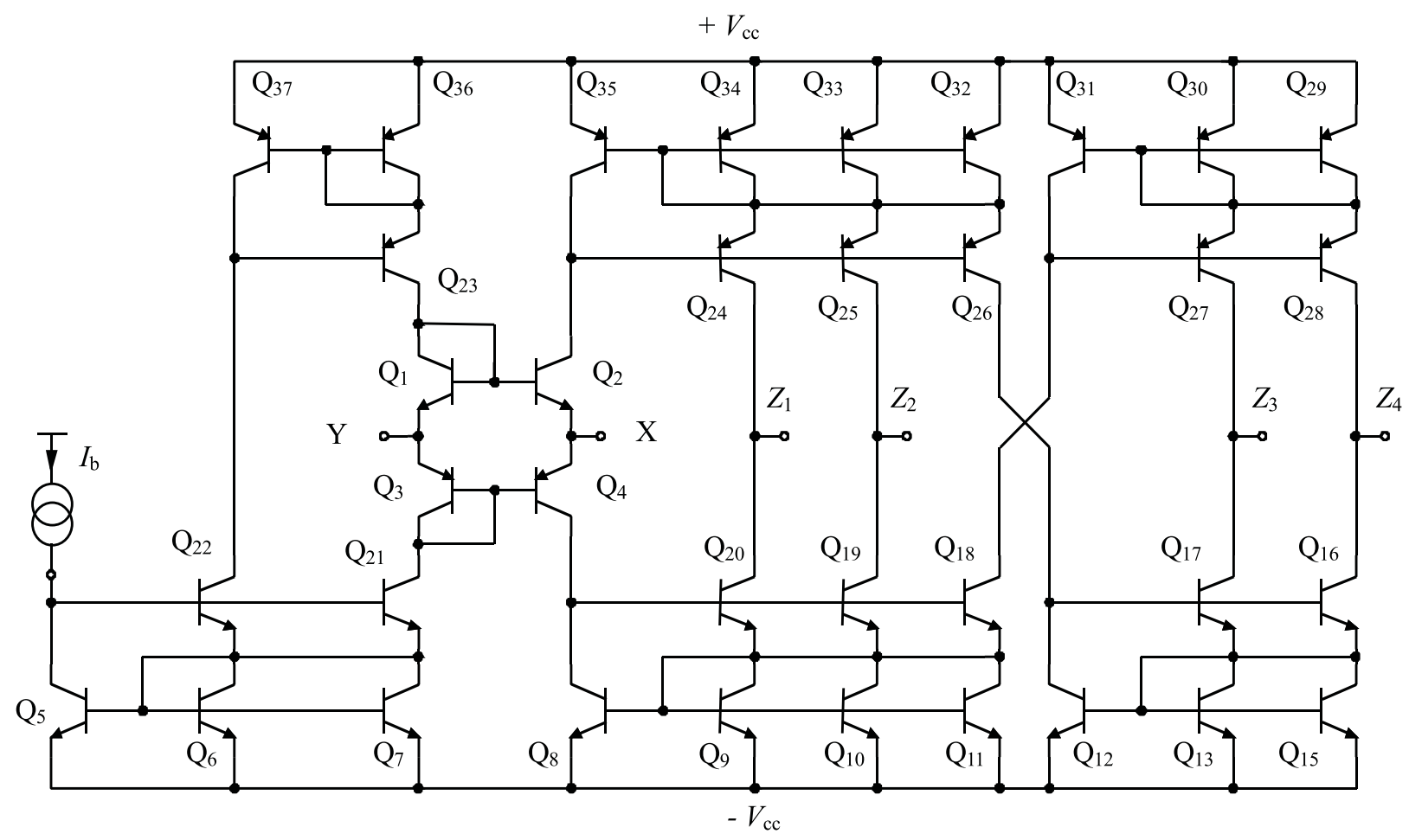

Fig. 2. Internal structure of MO-CCCII

Table 1. The internal parameters of the used bipolar transistors

\begin{tabular}{|c|c|c|c|c|c|}
\hline \multicolumn{6}{|c|}{ MODEL PNP6 PNP } \\
\hline$+\mathrm{IS}$ & $=2.015 \times 10^{-16}$ & $\mathrm{BF}$ & $=1.418 \times 10^{2}$ & $\mathrm{NF}=1.000$ & $\mathrm{VAF}=2.058 \times 10^{1}$ \\
\hline$+\mathrm{IKF}$ & $=1.085 \times 10^{-1}$ & ISE & $=2.233 \times 10^{-15}$ & $\mathrm{NE}=1.505$ & $\mathrm{BR}=3.252 \times 10^{1}$ \\
\hline$+\mathrm{NR}$ & $=1.050$ & VAR & $=1.093$ & $\mathrm{IKR}=5.000 \times 10^{-5}$ & $\mathrm{ISC}=6.621 \times 10^{-16}$ \\
\hline$+\mathrm{NC}$ & $=1.150$ & $\mathrm{RB}$ & $=3.346 \times 10^{1}$ & $\mathrm{IRB}=0.000$ & $\mathrm{RBM}=2.40$ \\
\hline$+\mathrm{RE}$ & $=5.537$ & $\mathrm{RC}$ & $=2.156 \times 10^{1}$ & $\mathrm{CJE}=1.202 \times 10^{-13}$ & $\mathrm{VJE}=7.320 \times 10^{-1}$ \\
\hline + MJE & $=4.930 \times 10^{-1}$ & $\mathrm{TF}$ & $=1.303 \times 10^{-11}$ & $\mathrm{XTF}=3.500 \times 10^{1}$ & $\mathrm{VTF}=3.259$ \\
\hline$+\mathrm{ITF}$ & $=2.639 \times 10^{-1}$ & $\mathrm{PTF}$ & $=0.000$ & $\mathrm{CJC}=1.595 \times 10^{-13}$ & $\mathrm{VJC}=7.743 \times 10^{-1}$ \\
\hline$+\mathrm{MJC}$ & $=5.000 \times 10^{-1}$ & XCJC & $\mathrm{C}=8.504 \times 10^{-2}$ & $\mathrm{TR}=1.500 \times 10^{-10}$ & $\mathrm{CJB}=7.620 \times 10^{-13}$ \\
\hline + VJS & $=9.058 \times 10^{-1}$ & MJS & $1 \times 10^{-1}$ & $\mathrm{XTB}=1.732$ & $\mathrm{EG}=1.184$ \\
\hline$+\mathrm{XTI}$ & $=2.000$ & $\mathrm{KF}$ & $10^{-16}$ & $\mathrm{ASF}=1.000$ & $\mathrm{FC}=8$ \\
\hline \multicolumn{6}{|c|}{ MODEL PNP6 NPN } \\
\hline$+\mathrm{IS}$ & $=70.400 \times 10^{-18}$ & $\mathrm{BF}$ & $=1.570 \times 10^{2}$ & $\mathrm{NF}=1.000$ & $\mathrm{VAF}=7.000 \times 10^{1}$ \\
\hline$+\mathrm{IKF}$ & $=39.750 \times 10^{-3}$ & ISE & $=32.190 \times 10^{-15}$ & $\mathrm{NE}=2.000$ & $\mathrm{BR}=0.7614$ \\
\hline$+\mathrm{NR}$ & $=1.000$ & VAR & $=1.452$ & $\mathrm{IKR}=81.720 \times 10^{-3}$ & $\mathrm{ISC}=7.618 \times 10^{-21}$ \\
\hline$+\mathrm{NC}$ & $=1.847$ & $\mathrm{RE}$ & $=5.537$ & $\mathrm{RB}=3.346 \times 10^{1}$ & $\mathrm{IRB}=0.000$ \\
\hline$+\mathrm{RBM}$ & $=2.400$ & $\mathrm{RC}$ & $=2.156 \times 10^{1}$ & $\mathrm{CJE}=120.20 \times 10^{-15}$ & $\mathrm{VJE}=0.7591$ \\
\hline + MJE & $=0.5406$ & CJC & $=133.80 \times 10^{-14}$ & $\mathrm{VJC}=0.6666$ & $\mathrm{MJC}=0.4509$ \\
\hline+ XCJC & $=8.450 \times 10^{-2}$ & TR & $=4.000 \times 10^{-11}$ & CJS $=3.180 \times 10^{-14}$ & $\mathrm{FC}=0.827$ \\
\hline$+\mathrm{TF}$ & $=12.130 \times 10^{-12}$ & XTF & $=2.049$ & $\mathrm{VTF}=1.813$ & $\mathrm{ITF}=42.930 \times 10^{-3}$ \\
\hline$+\mathrm{TR}$ & $=40.000 \times 10^{-12}$ & CJS & $=3.180 \times 10^{-14}$ & $\mathrm{EG}=1.184$ & $\mathrm{XTB}=1.022$ \\
\hline$+\mathrm{XTI}$ & $=1.780$ & $\mathrm{KF}$ & $=17.500 \times 10^{-15}$ & $\mathrm{AF}=1.000$ & $\mathrm{FC}=8.273 \times 10^{-1}$ \\
\hline
\end{tabular}

A lot of publications employing multiple-output curbeyond $1 \mathrm{GHz}$ is not a rarity. rent conveyors (MO-CC) in various modifications already exist [14-16]. The authors usually focus on electronic tun- 


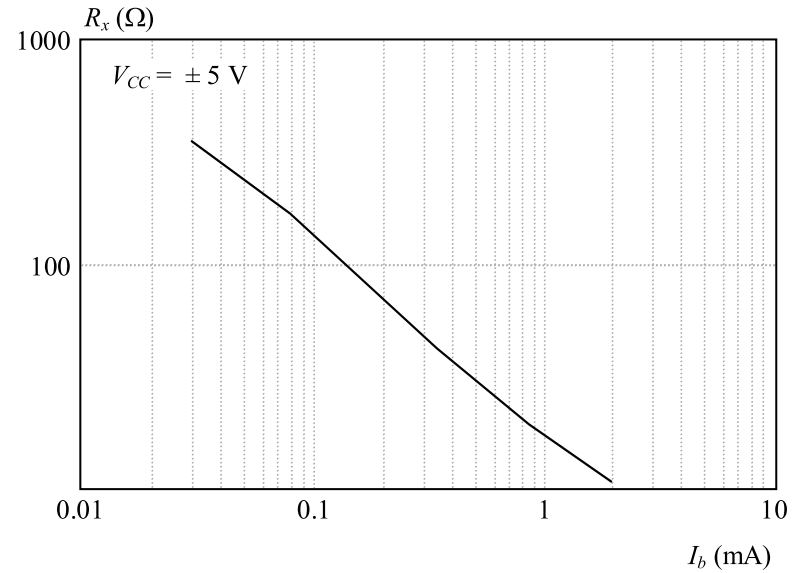

Fig. 3. The curve for $R_{x}=f\left(I_{b}\right)$ dependence

ing and on-chip implementation of the two current outputs. The principle of current conveyors (CC) itself is known for several decades and can be found in [3-5]. In practice, the nonzero input resistance of the current input node can be a problem. In the case of commercially available devices these value can reach tens of $\Omega$ and for a CMOS integrated circuits hundreds of $\Omega$ up to a few $\mathrm{k} \Omega$ $[16,17]$. The concrete value strongly depends on the biasing current. This drawback can be eventually turned into an advantage. It means that in specific situations some general property of the integrated circuit can be changed. For example, the time constant of the $\mathrm{CC}$ based voltage or current integrator can be instantly controlled. Among circuit designers the favourite OPA860 takes advantage of the mentioned event. We encourage the engineers to utilize the second generation MO-CCII given in Fig. 1.

Traditionally, for CCII $+[3,5]$ the orientations of all currents are towards the active block. In our case we use opposite directions as demonstrated in Fig. 1. The structure using Wilson current mirrors in bipolar technology [18] is given in Fig. 2. Two positive as well as two negative outputs are available. This quantity is sufficient for an overwhelming majority of applications. If not, additional mirrors can be connected analogically [13]. The models of individual transistors [10] are described in Tab. 1. The obtained dependence of $R_{x}=f\left(I_{b}\right)$ is in Fig. 3 .

\section{PROPOSED UNIVERSAL FILTER}

The signal flow graphs for particular configurations of the universal biquad filter are illustrated in Fig. 4. These configurations (transfer functions) can be established by using a single switch. The final circuitry with two CCCII-based integrators and two MO-CCCII distributors is given in Fig. 5. Note that this is the way how any transfer function can be realized, see Tab. 2 for further details. A filter with a desired transfer function never includes all four outputs of the active block. Thus, some current mirrors can be saved. For the higher-order circuits with this distributed network structures the demands for the number of distributor outputs raise.

Table 2. Concrete transfer function setup via switch position

\begin{tabular}{cccc}
\hline $\mathrm{SW}_{1}$ & $\mathrm{SW}_{2}$ & $\mathrm{SW}_{3}$ & TRANSFER TYPE \\
\hline on & off & off & high-pass (HP) \\
off & on & off & band-pass (BP) \\
off & off & on & low-pass (LP) \\
on & off & on & band-reject (BR) \\
on & on & on & all-pass (AP) \\
\hline
\end{tabular}

The individual transfer functions are following

$$
\begin{aligned}
& K_{L P}(s)=\frac{\frac{1}{R_{1}^{*} R_{2}^{*} C_{1} C_{2}}}{s^{2}+\frac{1}{R_{2}^{*} C_{2}} s+\frac{1}{R_{1}^{*} R_{2}^{*} C_{1} C_{2}}}, \\
& K_{B P}(s)=\frac{-\frac{1}{R_{2}^{*} C_{2}} s}{s^{2}+\frac{1}{R_{2}^{*} C_{2}} s+\frac{1}{R_{1}^{*} R_{2}^{*} C_{1} C_{2}}}, \\
& K_{H P}(s)=\frac{s^{2}}{s^{2}+\frac{1}{R_{2}^{*} C_{2}} s+\frac{1}{R_{1}^{*} R_{2}^{*} C_{1} C_{2}}}, \\
& K_{B R}(s)=\frac{s^{2}+\frac{1}{R_{1}^{*} R_{2}^{*} C_{1} C_{2}}}{s^{2}+\frac{1}{R_{2}^{*} C_{2}} s+\frac{1}{R_{1}^{*} R_{2}^{*} C_{1} C_{2}}}, \\
& K_{A P}(s)=\frac{s^{2}-\frac{1}{R_{2}^{*} C_{2}} s+\frac{1}{R_{1}^{*} R_{2}^{*} C_{1} C_{2}}}{s^{2}+\frac{1}{R_{2}^{*} C_{2}} s+\frac{1}{R_{1}^{*} R_{2}^{*} C_{1} C_{2}}},
\end{aligned}
$$

where $R_{1}^{*}=R_{1}+R_{x 1}$ and $R_{x 1}=f\left(I_{b 1}\right)$. For the characteristic frequency and quality factor it holds

$$
\omega_{C}=\sqrt{\frac{1}{R_{1}^{*} R_{2}^{*} C_{1} C_{2}}},
$$

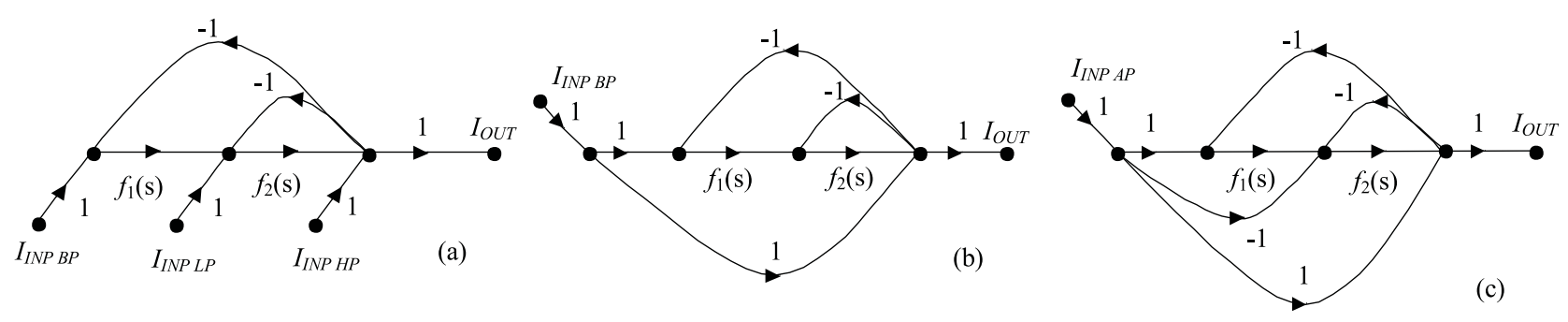

Fig. 4. Signal flow graph for low-pass, band-pass and high-pass filter (first picture), band-reject filter and all-pass filter 


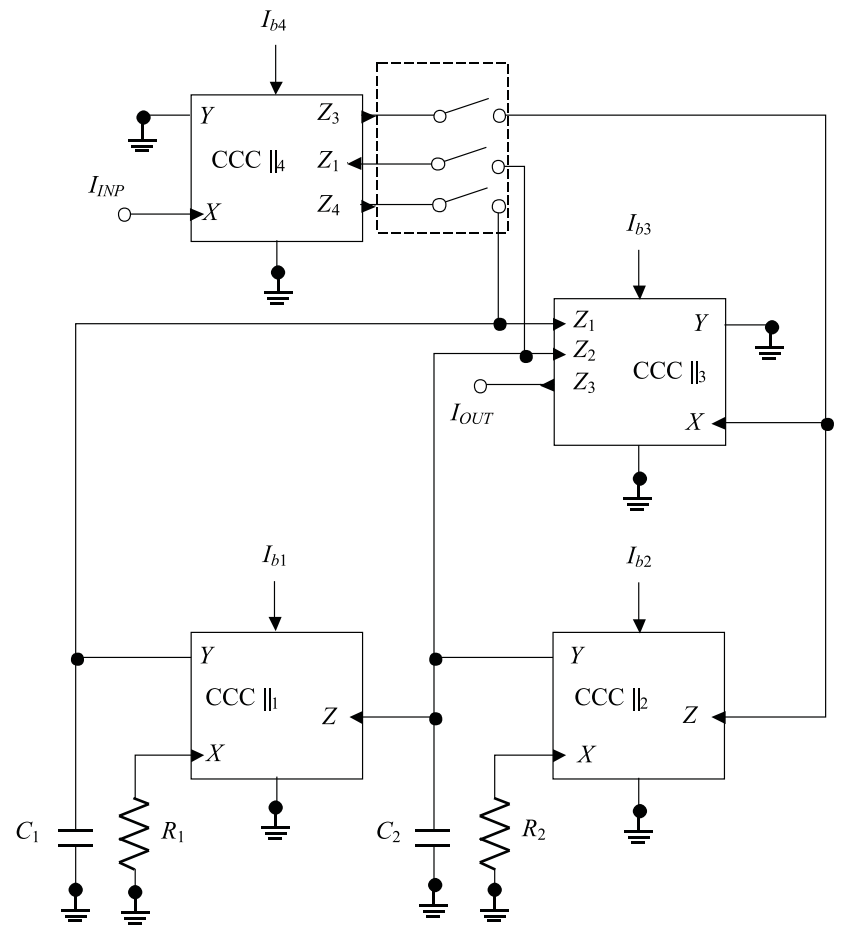

Fig. 5. Universal biquad

$$
Q=R_{2}^{*} C_{2} \sqrt{\frac{1}{R_{1}^{*} R_{2}^{*} C_{1} C_{2}}} .
$$

All relative sensitivities of $f_{C}$ on the changes of the circuit elements are -0.5 and the sensitivities of $Q$ are not greater than 1 .

\section{EXPERIMENTAL RESULTS}

As it is evident in the pictures below, the filter is designed for $f_{C}=2 \mathrm{MHz}$ with quality factor $Q=1$. The values of resistors are chosen as $R_{1}=R_{2}=R=50 \Omega$ and capacitors $C_{1}=C_{2}=C=220 \mathrm{pF}$. Using (6) and (7) one can easily calculate $R_{1}^{*}=R_{2}^{*}=R^{*}=362 \Omega\left(R_{x 1}=\right.$ $\left.R_{x 2}=R_{x}=312 \Omega\right)$. The mentioned $R_{x}$ gives $I_{b 1}=$ $I_{b 2}=I_{b}$ about $55 \mu \mathrm{A}$. The distributors control currents of $] 0 C C C I I_{3}$ and $\mathrm{CCCII}_{4}$ are $100 \mu \mathrm{A}$ and the supply voltage is $\pm 5 \mathrm{~V}$. The $3 \mathrm{~dB}$ gain drop for the highpass filter arises on the high frequency of $70 \mathrm{MHz}$. This value is well in the video range and represents the upper bound of the filter applicability. The verification of the achieved frequency characteristics (module only) is provided in Fig. 8. The entire frequency response of the all-pass filter is given in Fig. 7.

From the viewpoint of the cutoff frequency of the lowpass filter change (acquired frequency distance is $2.7 \mathrm{MHz}$ until about $12.2 \mathrm{MHz}$ ), electronic adjusting by means of the control currents $I_{b 1}=I_{b 2}$ is demonstrated in Fig. 8 with the parameters given in Tab. 3 .

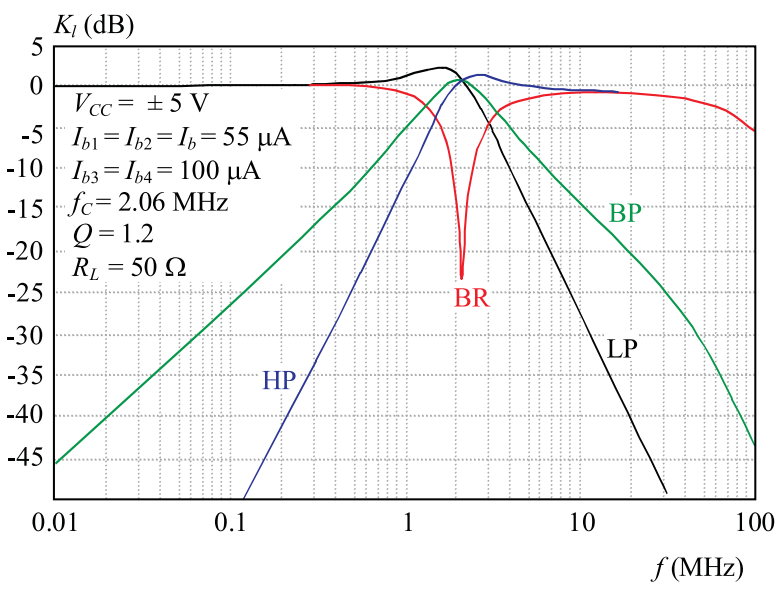

Fig. 6. Magnitude responses for low-pass, band-pass, high-pass and band-reject filters

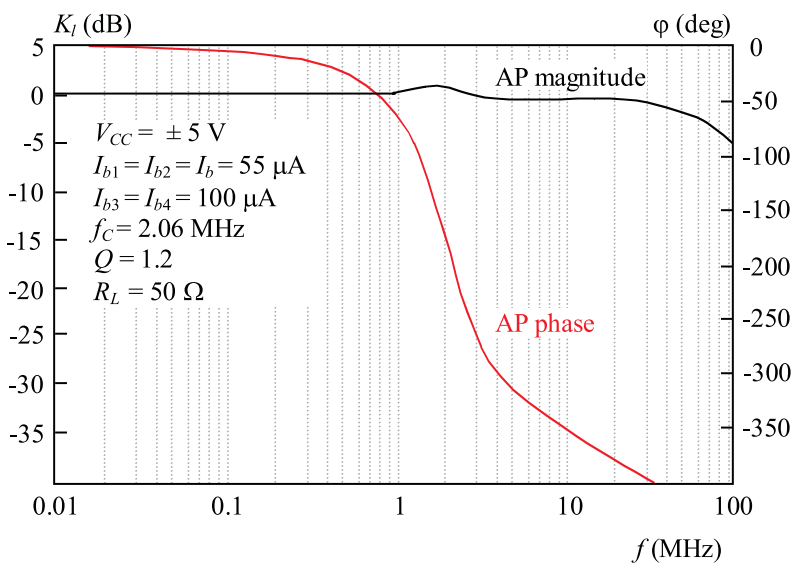

Fig. 7. Overall frequency response of all-pass filter

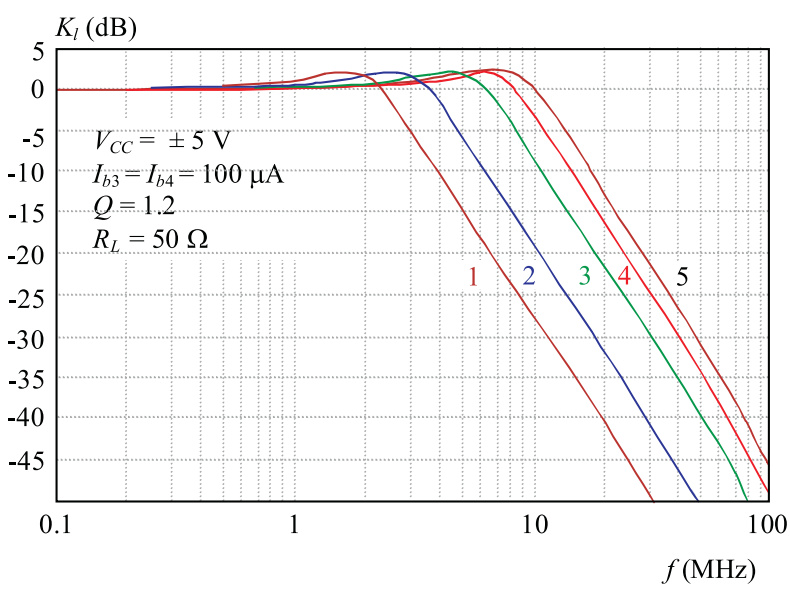

Fig. 8. Low-pass filter with electronic adjusting

Table 3. The values of the parameters in Fig. 8

\begin{tabular}{ccc}
\hline index & $I_{b 1}, I_{b 2}(\mu \mathrm{A})$ & $f_{-3 d B}(\mathrm{MHz})$ \\
\hline 1 & 55 & 2.76 \\
2 & 100 & 4.36 \\
3 & 250 & 7.63 \\
4 & 500 & 10.20 \\
5 & 1000 & 12.25 \\
\hline
\end{tabular}




\section{CONCLUSION}

This paper gives an idea concerning the filter with the multiple-output active blocks utilized for current distribution purpose. Evidently, the adequate solution with commercially available blocks (with single output) will be much more complicated. The employed MO-CCCII is great at good frequency response and in the possibility to turn the seeming disadvantage of $R_{x}=f\left(I_{b}\right)$ into the profitable control purpose. In the concrete filter network some CCCII current outputs can be omitted so that a bunch of transistors can be saved.

\section{Acknowledgement}

The research described in the paper was supported by the Czech Ministry of Education under research program MSM 0021630513 and Czech Science Foundation projects under Nos. 102/08/H027, 102/09/P217 and 102/09/1681. Research described in the paper is a part of the COST Action IC0803 RF/Microwave communication subsystems for emerging wireless technologies, financed by the Czech Ministry of Education by the grant no. OC09016.

\section{REFERENCES}

[1] TOumazou, C.-LidGey, E. J.-HAigh, D. G. : Analogue IC Design: The Current Mode Approach, Peter Peregrinus Ltd., London, 1990.

[2] DOSTAL, T.: Filters with Multi-Loop Feedback Structure in Current Mode, Radioengineering 12 No. 3 (2003), 6-11.

[3] BIOLEK, D.-SENANI, R.-BIOLKOVA, V.-KOLKA, Z. : Active Elements for Analog Signal Processing: Classification, Review, and New Proposal, Radioengineering 17 No. 4 (2008), $15-32$.

[4] JEŘÁBEK, J.-VRBA, K.: Vybrané vlastnosti univerzálního proudového konvejoru, ukázka návrhu aplikace, Elektrorevue 41 (2006), 1-9. (in Czech)

[5] PUNČOCHÁŘ, J.: Operační zesilovače v elektronice, BEN, Praha, 1997. (in Czech)

[6] Intersil (Elantec). EL 2082CN Current-Mode Multiplier, 1996, http://www.intersil.com.

[7] Analog Devices. Monolithic Op Amp AD 844. 2003, http://www.analog.com/.

[8] RANDALL, L. G.-SÁNCHEZ-SINENCIO, E.: Active Filter Design Using Operational Transconductance Amplifers: A Tutorial, IEEE Circuits and Devices Magazine 1 (1985), 20-32.

[9] Linear Technology, LT 1228 - $100 \mathrm{MHz}$ Current Feedback Amplifier with DC Gain Control. datasheets http://www.linear.com.

[10] Texas Instruments Inc. OPA 860 Wide Bandwidth Operational Transconductance Amplifier and Buffer, 2006 http://www.ti.com.
[11] Maxim Dallas Semiconductor. Wideband Transconductance Amplifiers MAX 435-436, http://www.maxim-ic.com.

12] WANG, C.-YHAO, Q.-DU, S.: A New Current-Mode SIMO-Type Universal Biquad Employing Multi-Output Current Conveyor, Radioengineering 18 No. 1 (2009), 83-88.

13] SANCHEZ-SINENCIO, E.-GEIGER, R. L.-NEWAREZ-LOZANO, H.: Generation of Continuous-Time Two Integrator Loop OTA Filter Structures, IEEE Transaction Circuits Systems 35 No. 8 (1988), 936-946.

[4] BIOLEK, D.-SIRIPRUCHYANUN, M.-JAIKLA, W. : CCII and OTA Based Current-Mode Universal Biquadratic Filter, The sixth PSU Engineering Conference, May 2008, pp. 238-241.

[15] JAIKLA, W.-SIRIPRUCHYANUN, M. : Low-Component Elekctronically Controlable Dual-Mode Universal Biquad Filter using DO-CCCIIs, In proceedings of Asia-Pacific conference on Communications, 2007, pp. 331-334.

16] SIRIPRUCHYANUN,M.-CHANAPROMMA,C.-SILAPAN, P.-JAIKLA,W.: BiCMOS Current-Controlled Current Feedback Amplifier (CC-CFA) and Its Applications, WSEAS Transactions on Electronics 5 No. 6 (2008), 203-219.

17] ELDBIB, I.-MUSIL, V.: Self-Cascode Current Controlled CCII Based-Tunable Band Pass Filter, Radiolektronika (2008), 119-122.

[18] BAKER, J.: CMOS Circuit Design, Layout and Simulation, IEEE Press Series on Microelectronic Systems (2005).

Received 22 April 2009

Roman Šotner was born in Znojmo, Czech Republic, in 1983. He received the MSc. degree (2008) from the Brno University of Technology. Currently he is a $\mathrm{PhD}$ student at the Faculty of Electrical Engineering and Communication. His interests are analogue circuits (active filters, oscillators, audio, etc.), circuits in the current mode and computer simulation.

Josef Slezák was born in Zlín, Czech Republic, in 1982. He received his MSc degree in 2007 from the University of Technology, Brno. He is currently studying his PhD study at the same university. His research interest is in analysis and design of analog circuits operating in current mode.

Tomáš Dostál was born in Brno, 1943. He received his $\mathrm{PhD}$ (1976) and DrSc degrees (1989) from the Brno University of Technology. He was with the Military Academy Brno (19761978, 1980-1984) and with the Military Technical College Baghdad (1978-1980). Since 1984 he has been with the Brno University of Technology as Professor of Radio-Electronics. His interests are in circuit theory, analogue filters, switched capacitor networks and circuits in the current mode.

Jiří Petržela was born in Brno, Czech Republic, in 1978. His research interest is chaos theory, circuit design. He received the MSc and PhD degrees from the Brno University of Technology in 2003 and 2007, respectively. Now he is assistant professor at the Department of Radio Electronics, Brno University of Technology. 